\title{
Effect of nitrogen fertilization on methane oxidation, abundance, community structure, and gene expression of methanotrophs in the rice rhizosphere
}

\author{
Minita Shrestha, Pravin Malla Shrestha, Peter Frenzel and Ralf Conrad \\ Department of Biogeochemistry, Max Planck Institute for Terrestrial Microbiology, Marburg, Germany
}

\begin{abstract}
Nitrogen, one of the limiting factors for the yield of rice, can also have an important function in methane oxidation, thus affecting its global budget. Rice microcosms, planted in the greenhouse, were treated with the $\mathrm{N}$-fertilizers urea (UPK) and ammonium sulfate (APK) or were only treated with phosphorous and potassium (PK). Methane oxidation rates in PK and UPK treatments were similar during most of the rice-growing season, revealing no effect of urea. However, ammonium sulfate strongly suppressed methanogenesis providing an unfavorable environment for methanotrophs in APK treatment. Roots and rhizospheric soil samples, collected from six different growth stages of the rice plant, were analyzed by terminal restriction fragment length polymorphism (T-RFLP) of the pmoA gene. Assignment of abundant T-RFs to cloned pmoA sequences indicated that the populations on roots were dominated by type-I methanotrophs, whereas the populations in rhizospheric soil were dominated by type-II methanotrophs irrespectively of growth stages and fertilizer treatments. Non-metric multidimensional scaling ordination analysis of T-RFLP profiles revealed that the methanotrophic community was significantly $(P<0.001)$ affected by the different fertilizer treatments; however, the effect was stronger on the roots than in the rhizospheric soil. Contrary to $p m o A$ gene-based analysis, $p m o A$ transcript-based T-RFLP/cloning/sequencing analysis in rhizospheric soil showed type $I$ as the predominant methanotrophs in both PK and UPK treatments. Collectively, our study showed that type-I methanotrophs were dominant and probably active in rhizospheric soil throughout the season irrespective of nitrogen fertilizer used, whereas type-II methanotrophs were relatively more dominant under unfavorable conditions, such as in APK treatment.
\end{abstract}

The ISME Journal (2010) 4, 1545-1556; doi:10.1038/ismej.2010.89; published online 1 July 2010

Subject Category: microbial population and community ecology

Keywords: methane oxidation; methanotroph; nitrogen fertilization; rhizosphere; rice field; $p m o A$ gene; pmoA transcript

\section{Introduction}

Rice paddies are one of the major contributors to the emission of the greenhouse gas methane. Approximately $10-30 \%$ of the $\mathrm{CH}_{4}$ produced by methanogens in rice paddies is consumed by aerobic methaneoxidizing bacteria (methanotrophs) associated with the roots of rice plants (Neue et al., 1997; Kruger et al., 2002), thereby mitigating $\mathrm{CH}_{4}$ emission.

Understanding $\mathrm{CH}_{4}$ fluxes from rice paddy fields requires understanding of methanotrophic bacteria and their controlling factors. Besides methane and oxygen, nitrogen can also have an important function in $\mathrm{CH}_{4}$ oxidation and may become an inhibiting or stimulating factor for growth of methanotrophs. Currently, there are many contradictory findings

Correspondence: R Conrad, Terrestrische Mikrobiologie, Max Planck Institute for Terrestrial Microbiology, Abteilung Biogeochemie, Karl-von-Frisch-Strasse10, D-35043 Marburg, Germany. E-mail: conrad@mpi-marburg.mpg.de

Received 18 March 2010; revised 17 May 2010; accepted 17 May 2010; published online 1 July 2010 reporting inhibition effects (Steudler et al., 1989; Bosse et al., 1993; Hutsch et al., 1994), stimulation effects (Bodelier et al., 2000b; Kruger and Frenzel, 2003), or no effects (Dunfield et al., 1995; Delgado and Mosier, 1996; Dan et al., 2001) of ammoniumbased N-fertilization on methanotrophs.

Few studies showed that type-I methanotrophs are stimulated by the addition of nitrogen fertilizer (Bodelier et al., 2000b; Noll et al., 2008; Qiu et al., 2008). However, these studies were based on a single-time point sampling. The question arises whether the community composition of total and metabolically active methanotrophs is shaped differently by different nitrogen availability at different time points during the rice-growing season. Therefore, in this study, we tried to give a comprehensive overview of methanotrophs (except Verrucomicrobia and Crenothrix) in planted rice microcosm by investigating the effect of different $\mathrm{N}$-fertilizers (urea and ammonium sulfate). For this purpose, we combined process measurements with potential activity assay, quantitative PCR assay of $p m o A$ gene, 
and terminal restriction fragment length polymorphism (T-RFLP) fingerprinting/cloning and sequencing of $p m o A$ gene and $p m o A$ transcripts.

\section{Materials and methods}

Planted rice microcosms

Soil was taken from drained paddy fields of the Italian Rice Research Institute in Vercelli, Italy, in 2006 and was air dried and stored at room temperature. The soil contained $1.43 \%$ C, $0.13 \%$ $\mathrm{N}$, and had a texture consisting of $14 \%$ clay, $61 \%$ silt, and $27 \%$ sand. The soil slurry for 75 pots was prepared by mixing $120 \mathrm{~kg}$ soil, $67.5 \mathrm{l}$ demineralized water, and divided into three equal parts. Two 25-l slurry portions were mixed separately with $1.25 \mathrm{l}$ $\mathrm{N}$-fertilizer solutions [per liter: $0.87 \mathrm{~g}$ phosphorous (P) as $\mathrm{KH}_{2} \mathrm{PO}_{4}, 1.85 \mathrm{~g}$ potassium $(\mathrm{K})$ as $\mathrm{KCl}$, and $2.3 \mathrm{~g}$ nitrogen (N) as urea (UPK) or ammonium sulfate (APK)]. Similarly, a third 25-l slurry portion was mixed with fertilizer without adding nitrogen source and treated as control (PK). Soil slurry was then filled into 75 pots with a volume of $1.6 \mathrm{l}$ (height $11 \mathrm{~cm}$, diameter $16 \mathrm{~cm}$ ) and these microcosms were flooded with demineralized water up to $5 \mathrm{~cm}$ water depth above the soil surface. This water depth was maintained throughout the experimental period. The amounts of fertilizer added correspond per ha to $160 \mathrm{~kg} \mathrm{~N}$ as urea or ammonium sulfate, $140 \mathrm{~kg}$ $\mathrm{P}_{2} \mathrm{O}_{5}$, and $155 \mathrm{~kg} \mathrm{~K}_{2} \mathrm{O}$; such amounts are common in rice field agriculture. In the center of each pot, a self-made nylon bag $(25 \mu \mathrm{m}$ mesh; $6 \mathrm{~cm}$ length and $9 \mathrm{~cm}$ radius) was placed through which water and nutrients could pass freely, whereas roots were not able to penetrate, isolating the roots and surrounding soil inside the bag as rhizospheric soil from the bulk soil outside the bag (Supplementary Figure S1).

After 5 days of flooding, one 12-day-old rice seedling (Oryza sativa var. KORAL type japonica) was transplanted into the center of the nylon bag in each pot and $50 \mathrm{ml}$ fertilizer solution was added as a second fertilization. The day of transplantation was taken as day zero and the incubation experiment was then conducted for total 88 days under flooded conditions in the greenhouse (RH-70\%, $12 \mathrm{~h}$ photoperiod, and $28 / 22^{\circ} \mathrm{C}$ day/night temperature). On day 57 , a third and final dose of $50 \mathrm{ml}$ fertilizer solution was added to each microcosm.

Plant parameters, $\mathrm{CH}_{4}$ flux, pore water $\mathrm{CH}_{4}, \mathrm{pH}, \mathrm{NH}_{4}^{+}$, $\mathrm{NO}_{2}^{-}$, and $\mathrm{NO}_{3}^{-}$

Once a week, total plant height (from the soil surface), tiller number, and leave number were noted. Rates of $\mathrm{CH}_{4}$ emission and $\mathrm{CH}_{4}$ oxidation in triplicate microcosms were measured as described earlier (Kruger and Frenzel, 2003; Shrestha et al., 2008). Pore water samples were collected weekly from the rhizosphere $(3 \mathrm{~cm}$ depth from the soil surface) and bulk (10 $\mathrm{cm}$ depth from the soil surface) soil of rice microcosms using stoppered tubes as described by Shrestha et al. (2008). After shaking the tube with pore water, an aliquot of the gas headspace was sampled using pressure lock syringes and analyzed for $\mathrm{CH}_{4}$ concentration and the pore water was analyzed for $\mathrm{pH}, \mathrm{NH}_{4}^{+}, \mathrm{NO}_{2}^{-}$, and $\mathrm{NO}_{3}^{-}$as described earlier (Kruger et al., 2001; Shrestha et al., 2008).

\section{Collection of soil and root samples}

Destructive sampling technique was used to collect samples of rhizospheric soil and roots from the planted rice microcosms. Samples were repeatedly collected in triplicate from three microcosms and three different fertilizer treatments ( 3 samples $\times 3$ microcosms $\times 3$ treatments) on day 29 after transplantation. Rhizospheric soil is defined as the soil present inside the nylon bag closely adhered to roots. Nylon mesh bag with rice plant was pulled out carefully and then the upper $2-3 \mathrm{~cm}$ soil surface layer was removed and discarded. Rhizospheric soil sample was then collected by homogenizing the remaining soil that is present inside the bag and was immediately suspended in RNAlater (Ambion, Darmstadt, Germany). After $24 \mathrm{~h}$ of incubation at $4{ }^{\circ} \mathrm{C}$, samples were centrifuged at $5000 \mathrm{~g}$ for $5 \mathrm{~min}$, and the supernatant was discarded. The soil samples were then washed twice with one quarterstrength Ringer solution to remove the remaining RNAlater (Shrestha et al., 2009). Roots samples were treated in the same way except that they were first washed with sterile demineralized water and pulverized with a mortar and pestle after shock freezing in liquid nitrogen. Soil and root samples thus obtained were processed immediately or stored at $-80^{\circ} \mathrm{C}$ for later molecular analysis. Similarly, samples were collected on 40, 57, 62, 67, and 88 days after transplantation and processed.

\section{Methane oxidation potential}

Methane oxidation potential was determined for triplicate rhizospheric soil samples collected on 29, $40,57,62,67$, and 88 days after transplantation from all three treatments. Soil slurries were prepared by mixing $1 \mathrm{~g}$ moist soil with $1 \mathrm{ml}$ sterile demineralized $\mathrm{H}_{2} \mathrm{O}$ and were placed into $25-\mathrm{ml}$ pressure tubes closed with butyl stoppers. The tubes were flushed with synthetic air $\left(21 \% \mathrm{O}_{2}\right.$ in $\left.\mathrm{N}_{2}\right)$ for $1 \mathrm{~min}$, and then the headspace was supplemented with $50000 \mathrm{ppmv}$ $\mathrm{CH}_{4}$. The tubes were then incubated horizontally on a roller (at 150 r.p.m.) at $30^{\circ} \mathrm{C}$ in dark. Headspace $\mathrm{CH}_{4}$ was sampled at $0,2,18,24,42,48,66$, and $72 \mathrm{~h}$ after incubation using a pressure lock syringe, and the concentration was measured by gas chromatography (Kruger et al., 2002). The $\mathrm{CH}_{4}$ concentration started to decrease right after the incubation. From the $\mathrm{CH}_{4}$ depletion of triplicate samples, linear regressions were calculated and potential $\mathrm{CH}_{4}$ oxidation rates were determined from the slope of the regression. 
DNA and RNA extraction

DNA and RNA from the soil and roots samples were extracted using the protocol reported earlier (Shrestha et al., 2008, 2009) with few modifications. For the total RNA extraction, total nucleic acid was treated with $5 \mathrm{U}$ DNAse (Promega, Mannheim, Germany), $10 \times$ DNAse buffer (Promega), in combination with $10 \mathrm{U}$ RNAsin (Promega), and incubated at $37^{\circ} \mathrm{C}$ for $1 \mathrm{~h}$. Finally, total RNA was further purified by using RNeasy kit (Qiagen, Hilden, Germany). The integrity of the $16 \mathrm{~S}$ and $23 \mathrm{~S}$ rRNA was checked by electrophoresis on a $1 \%$ agarose gel and purity was checked using nanodrop spectrophotometer (NanoDrop Technologies, Wilmington, USA) by measuring the absorbance ratio at 260/ $280 \mathrm{~nm}$, which was consistently found to be $>1.8$.

\section{PCR of pmoA gene and RT-PCR of pmoA transcript}

PCR amplification of the $p m o A$ gene was performed using primers A189f and mb661r as described earlier (Shrestha et al., 2008). For RT-PCR of pmo $A$ transcripts, two-steps RT-PCR was performed using the ImProm-II Reverse Transcription System (Promega). In the first step, cDNA was synthesized in a total volume of $20 \mu \mathrm{l}$ at $45^{\circ} \mathrm{C}$ for $45 \mathrm{~min}$. The reaction volume contained $2 \mu \mathrm{l}$ template RNA and 20 pmol A682r primer. In the second step, touchdown PCR was performed using $1 \mu \mathrm{l}$ cDNA template from the RT step. Touchdown PCR program includes initial denaturation for $3 \mathrm{~min}$ at $94^{\circ} \mathrm{C}$, followed by 11 touchdown cycles consisting of denaturation at $94{ }^{\circ} \mathrm{C}$ for $1 \mathrm{~min}$, primer annealing at $64-55^{\circ} \mathrm{C}$ (with $-1{ }^{\circ} \mathrm{C}$ decrease in annealing temperature per cycle) for $1 \mathrm{~min}$ and 24 further cycles at $55^{\circ} \mathrm{C}$ for $1 \mathrm{~min}$, followed by extension at $72{ }^{\circ} \mathrm{C}$ for $1 \mathrm{~min}$. The final elongation step was extended to $7 \mathrm{~min}$. An aliquot $(1 \mu \mathrm{l})$ of the PCR product from the A189f/A682r primer set was used for the second round of PCR with primer set A189f/mb661r. The PCR program was initial denaturation at $94{ }^{\circ} \mathrm{C}$ for $2 \mathrm{~min}$; 15 cycles of denaturation at $94{ }^{\circ} \mathrm{C}$ for $1 \mathrm{~min}$, primer annealing at $62{ }^{\circ} \mathrm{C}$ for $30 \mathrm{~s}$, and elongation at $72{ }^{\circ} \mathrm{C}$ for $1 \mathrm{~min}$ followed by another 20 cycles of denaturation at $94{ }^{\circ} \mathrm{C}$ for $1 \mathrm{~min}$, primer annealing at $55^{\circ} \mathrm{C}$ for $30 \mathrm{~s}$, and elongation at $72{ }^{\circ} \mathrm{C}$ for $1 \mathrm{~min}$. The final elongation step was extended to $7 \mathrm{~min}$. In parallel to the RT-PCR reaction, a control RT-PCR in the absence of reverse transcriptase enzyme was conducted for all samples to verify the absence of DNA.

\section{T-RFLP analysis}

T-RFLP analysis was performed for both DNA and cDNA samples in triplicate as described earlier (Shrestha et al., 2008). For cDNA samples, an aliquot $(1 \mu \mathrm{l})$ of the PCR product from the A189f/ A682r primer set, as described above, was used for a second round of PCR with primer set A189f/mb661r in which an FAM (6-carboxyfluorescein)-labeled forward primer was used. However, using reverse primer mb661r in conjunction with labeled forward primer A189f did not give any PCR products for root samples taken after 57 and 88 days of APK treatment and nine cDNA samples from three treatments taken on 62, 67, and 88 days after transplantation. Therefore, a degenerate reverse primer, nmb650r (ACGTCYTTACCGAAVGT), was designed based on the 650r primer (Bourne et al., 2001) and was used for the PCR amplification of the above 11 samples for T-RFLP analysis. The PCR program was performed as described above. Before performing T-RFLP assay, the performance of the new reverse primer was tested against mb661r primer using seven randomly chosen samples (DNA and cDNA products from soil and roots), which were successfully amplified before by using A189f/mb661r primer set in T-RFLP analysis. The result showed that both A189f/mb661r and A189f/ nmb650r primer sets gave highly similar T-RFLP patterns (Supplementary Figure S2). The final PCR products were gel purified by using Wizard SV Gel and PCR Cleanup System (Promega) before performing T-RFLP assay.

The length of fluorescently labeled T-RFs was determined by comparison with the internal standard using GeneScan 3.71/5.1 software (Applied Biosystems, Darmstadt, Germany). The relative abundance of T-RFs was calculated as described before (Shrestha et al., 2008). Here, T-RFLP patterns of three replicates from the same microcosm as well as from three replicate microcosms of each treatment were analyzed for tube-to-tube and pot-to-pot variations. Variation among the replicates was checked for major T-RF peaks, which was very small. Therefore, the relative abundances of T-RFs of all the replicates (5-9 replicates) were averaged for each treatment and time points.

\section{Quantification of pmoA gene by real-time PCR}

Methanotrophs were quantified in root and rhizospheric soil samples by using the pmoA-targeting real-time PCR assay using A189f/mb661r primers. Cloned pmoA gene fragments were used to create the standard curve as earlier described (Kolb et al., 2003). Before quantification, the DNA extracts were tested for inhibitory effects of co-extracted substances (Kolb et al., 2003) and the lowest dilution that had no inhibitory effect was used for further measurements.

Real-time PCR assays were performed using iCyler IQ thermocycler (Bio-Rad, Munich, Germany). Reaction solutions contained $12.5 \mu \mathrm{l}$ Sybr Green Jumpstart Taq Ready mix (Sigma-Aldrich, Munich, Germany), $4 \mu \mathrm{l} \mathrm{MgCl}_{2}, 0.5 \mu \mathrm{l}$ BSA, $0.6 \mu \mathrm{M}$ each primer (MWG Biotech, Ebersberg, Germany), $5 \mu \mathrm{l}$ DNA template, and $3 \mu \mathrm{l}$ purified water. Each measurement was performed in four replicates in $25 \mu \mathrm{l}$ volumes. Data analysis was carried out with iCyler software version 2.3.1370 (Bio-Rad). A single peak in the melting curve analysis and a single band in the agarose gel staining confirmed specific amplification of pmo $A$ gene. 
Cloning, sequencing, and phylogenetic analysis

A total of nine clone libraries were generated. Six libraries were constructed from the pooled pmoA gene PCR product of soil and root samples taken 57 days after transplantation for each of the three different fertilizers treatments. The other three clone libraries were constructed from the pooled pmoA RT-PCR products of rhizospheric soils taken 40 days after transplantation for each of the three different fertilizers treatment. The pGEM-T Easycloning kit (Promega) was used for the cloning following the manufacturer's instructions. A total of 166 clones from the $p m o A$ gene PCR and 88 clones from the pmoA RT-PCR were randomly selected and cloned inserts were sequenced using the primers M13f- and M13r-targeting vector sequences. The sequences were analyzed initially using the BLASTn tool (Altschul et al., 1990). All the sequences together with the closest matched sequences in BLASTn were then imported into ARB (Ludwig et al., 2004) for phylogenetic tree construction. Regions of sequence ambiguity and incomplete data were excluded from the analyses. The results were depicted as a consensus tree, combining the results of Tree-Puzzle, Neighbor-joining, and Maximum likelihood analyses of the datasets.

\section{Statistical analysis}

One-way ANOVA and Duncan post hoc test was used for testing significant differences between treatments for the in situ $\mathrm{CH}_{4}$ oxidation rates, $\mathrm{CH}_{4}$ oxidation potentials, and real-time PCR results using SPSS software (version 11.5).

All other statistical analyses were performed in $\mathrm{R}$ (version 2.9.1; R Development Core Team, Vienna, Austria). Environmental parameters, $\mathrm{CH}_{4}$ fluxes, and molecular analyses could not always be measured on the same day and/or on the same microcosm(s). Hence, a non-linear local fit of environmental data against time was used to analyze controlling factors. The fits were constructed with LOCFIT (http:// cran.r-project.org/web/packages/locfit/) and $\alpha=0.3$. The parameter $\alpha$ controls how closely the fit follows short-term deviations from the general trend. The value $\alpha=0.3$ was chosen as the best compromise between generalization and over-fitting after visually inspecting fits with $\alpha$ varying from 0.6 to 0.3. An example is given in Supplementary Figure S3. T-RFLP data as retrieved from the sequencer were re-formatted with package reshape (version 0.8.3; Wickham, 2007) into a rectangular matrix for further analysis. T-RFs were standardized according to Dunbar et al. (2001). Multivariate analyses were performed with vegan (Oksanen, 2008). For all community analyses, Bray-Curtis dissimilarities were used. We used non-metric multidimensional scaling (NMDS) for ordinations and the function metaMDS in particular. Differences in community patterns between treatments were tested with analysis of similarity. Correlations between communities and environmental factors were tested with ADONIS. Both analysis of similarity and ADONIS were run with 1000 permutations.

\section{Nucleotide sequence accession numbers}

DNA sequences of $p m o A$ gene and cDNA sequences of pmoA transcripts have been deposited in the EMBL, GenBank, and DDBJ nucleotide sequence databases under accession no. FN649469 to FN649634 and FN649638 to FN649725, respectively.

\section{Results}

Rates of $\mathrm{CH}_{4}$ emission and oxidation

Vegetative growth of rice plants (plant height, number of tiller, and number of leaves) was more pronounced in APK than UPK and PK treatments (Supplementary Figure S4). Plant growth was similar in PK and UPK till 57 days, but after 57 days, that is after the third fertilization, number of tillers and leaves increased in UPK as compared with PK treatment.

Methane emission rates (in the absence of inhibitor) gradually increased from the beginning and reached maximum values (19-21 mg $\mathrm{CH}_{4} \mathrm{~m}^{-2} \mathrm{~h}^{-1}$ ) on days 48 and 65 in PK and UPK treatments, respectively (Figure 1a). However, the differences in $\mathrm{CH}_{4}$ emission rates in PK and UPK treatments were not significant $(P>0.05)$ except on days 43 and 67. In APK treatment, in contrast, $\mathrm{CH}_{4}$ emission rates remained $<3 \mathrm{mg} \mathrm{CH}_{4} \mathrm{~m}^{-2} \mathrm{~h}^{-1}$ during most of the incubation period.

Methane oxidation started to increase after day 30 and reached maximum values (7-11 mg $\mathrm{CH}_{4} \mathrm{~m}^{-2} \mathrm{~h}^{-1}$ ) on days 48 and 43 in PK and UPK treatments, respectively (Figure 1b). These rates attenuated nearly $28 \%$ (PK) and $50 \%$ (UPK) of the anaerobically produced $\mathrm{CH}_{4}$. In APK treatment, in contrast, $\mathrm{CH}_{4}$ oxidation rates were always very low ( $<1 \mathrm{mg} \mathrm{CH}_{4} \mathrm{~m}^{-2} \mathrm{~h}^{-1}$ ) (Figure 1b).

\section{Methane and other compounds in the pore water}

The highest $\mathrm{CH}_{4}$ concentrations were about $400 \mu \mathrm{M}$ (rhizospheric soil) and $800 \mu \mathrm{M}$ (bulk soil) in PK (on days 20 and 35) and UPK treatments (on days 30 and 35; Figures 1c and d). From days 30 to 60, these values decreased to about $200 \mu \mathrm{M}$ in the rhizospheric soil and then again increased in the late ricegrowing season. In APK treatment, $\mathrm{CH}_{4}$ concentrations were always $<150 \mu \mathrm{M}$ (Figures 1c and d).

In PK treatment, $\mathrm{NH}_{4}^{+}$concentration was about $2 \mathrm{mM}$ at the beginning, but undetectable later on (Figures 1e and f). In APK and UPK treatments, $\mathrm{NH}_{4}^{+}$ concentrations were in the range of $15-20 \mathrm{mM}$ at the early days and decreased rapidly after 18 days in both rhizospheric and bulk soil. In both, UPK and APK treatments, a small peak of $\mathrm{NH}_{4}^{+}(2-3 \mathrm{mM})$ was observed in rhizospheric region after fertilizer addition (Figure 1e) on day 57. The $\mathrm{NO}_{2}^{-}$and 

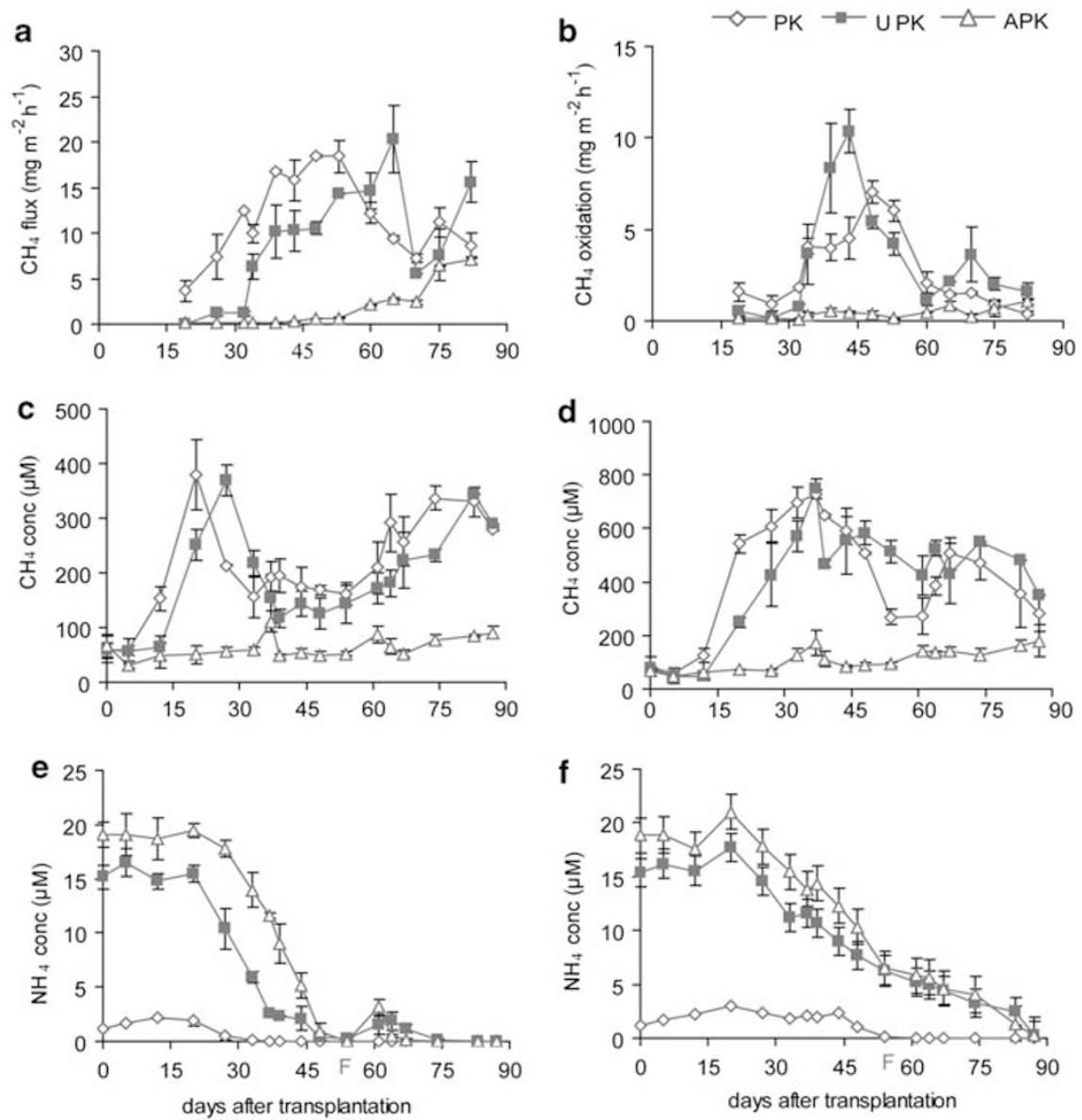

Figure 1 (a) Methane emission rates, (b) $\mathrm{CH}_{4}$ oxidation rates, (c) pore water $\mathrm{CH}_{4}$ concentrations in rhizospheric soil, (d) pore water $\mathrm{CH}_{4}$ concentrations in bulk soil, (e) pore water $\mathrm{NH}_{4}^{+}$concentrations in rhizospheric soil, and (f) pore water $\mathrm{NH}_{4}^{+}$concentrations in bulk soil in PK, UPK, and APK treatments. 'F' on the horizontal axis stands for the day on which final dose of fertilizer solution was added; values are mean \pm s.d. $(n=3-9)$.

$\mathrm{NO}_{3}^{-}$concentrations were generally below the detection limit $(<5 \mu \mathrm{M})$. The $\mathrm{pH}$ was in the range of 6.5-7.5 in both rhizospheric and bulk soil.

\section{Methane oxidation potential}

Methane oxidation started without lag in all rhizospheric soil samples (PK, UPK, APK) (Figure 2). The $\mathrm{CH}_{4}$ oxidation potentials (MOP) were significantly lower $(P<0.01)$ in PK than UPK treatment at almost all sampling points. There was no significant difference $(P>0.01)$ in MOP of the two nitrogen fertilizer treatments (UPK, APK) until day 57. However, MOP decreased significantly $(P<0.01)$ in APK treatment after 62 days and then remained significantly $(P<0.01)$ lower compared with UPK treatment (Figure 2).

\section{Quantitative PCR of pmoA}

Copy numbers of the $p m o A$ gene were measured in all samples except roots from day 29. The pmoA copy numbers in PK and UPK, but not in APK treatment, varied significantly $(P<0.05)$ over time in

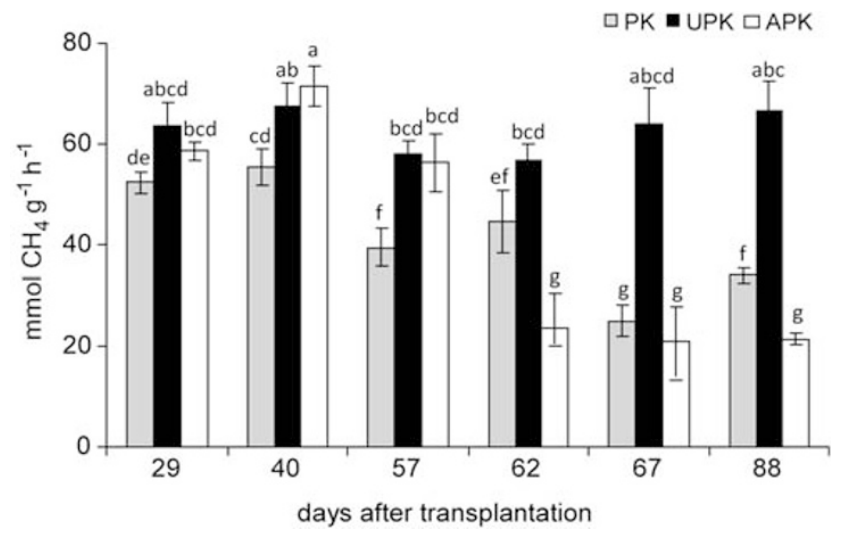

Figure 2 Methane oxidation potentials measured in rhizospheric soil samples from different sampling periods in PK, UPK, and APK treatments; values are mean \pm s.d. $(n=3)$. Letters on top of the bar indicate results from a Duncan post hoc test of a one-way ANOVA. Different letters indicate significant differences $(P<0.01)$ between the means of the different treatments.

both roots and rhizospheric soil. The pmoA copy numbers were always lower in APK than in PK and UPK treatments for most of the sampling time points 

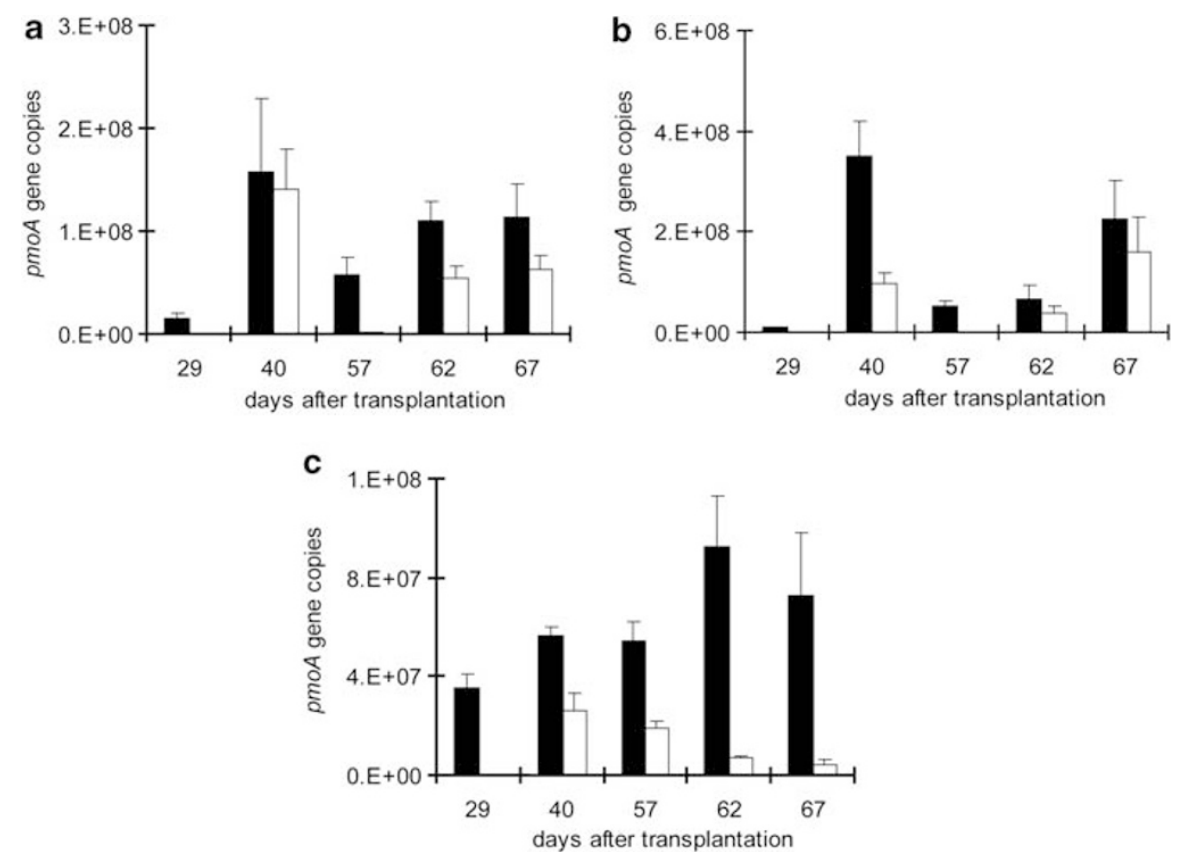

Figure 3 Copy numbers of $p m o A$ genes in rhizospheric soil (black bars) and on roots (white bars) from (a) PK, (b) UPK, and (c) APK treatments; values are mean \pm s.d. $(n=4)$.

(Figure 3). On root samples, copy numbers were significantly lower $(P<0.05)$ in PK than UPK treatment on day 67 , but significantly $(P<0.05)$ higher on day 40. In rhizospheric soil, copy numbers were significantly lower $(P<0.05)$ in PK than UPK treatment on days 40 and 67 (Figure 3). Copy numbers were positively correlated (Spearman's rank correlation) with $\mathrm{CH}_{4}$ oxidation rates in UPK $(R=0.77 ; P<0.001)$ and APK $(R=0.68 ; P<0.001)$.

\section{T-RFLP and cloning/sequencing of pmoA gene and pmoA transcripts}

Most of the T-RFs that were obtained from roots and rhizospheric soil (Figures 4-6) could be assigned to respective genera of type-I and type-II methanotrophs by our clone sequences, that is $80 \mathrm{bp}=$ Methylococcus, Methylocaldum, uncultured type-I methanotrophs; $245 \mathrm{bp}=$ Methylocystis, Methylosinus; $438 \mathrm{bp}=$ Methylomonas; $457 \mathrm{bp}=$ Methylomicrobium; $506 \mathrm{bp}=$ Methylobacter; 227, 242, 350, and $374 \mathrm{bp}=$ uncultured type-I methanotrophs (Supplementary Figure S5). However, T-RFs of 113, 210, 264, 278,364 , and $448 \mathrm{bp}$ could not be assigned to any of the sequences obtained from the clone libraries.

T-RFLP patterns of $p m o A$ genes on roots showed a high relative abundance of the $438 \mathrm{bp}$ T-RF in UPK treatment, except on day 88 (Figure 4b). The T-RFLP patterns were more dynamic in PK and APK treatments than in UPK (Figures 4a and c). T-RFLP patterns of $p m o A$ genes in rhizospheric soil showed that the T-RF of 245 bp generally comprised $60-90 \%$ of the total abundance in all treatments, except for PK on day 29 , when it constituted only $42 \%$ of the total, but still being the relatively most abundant T-RF (Figures 5a-c).

Unfortunately, transcripts of pmoA could not be retrieved using root samples. In rhizospheric soil samples, the T-RFLP patterns of the pmoA transcripts in PK and UPK treatments, but not in APK treatment, showed a clear temporal variation over the growth stages (Figures 6a-c). A similar tendency was also revealed by clone frequency (data not shown). In PK and UPK treatments, the major T-RFs were $80,245,350$, and $438 \mathrm{bp}$, which all changed over time. In APK treatment (Figure 6c), in contrast, the T-RF of $245 \mathrm{bp}$ was generally the dominant one with $>48 \%$ of total abundance. Overall, relative abundance of type-I methanotrophic transcripts was high in PK and UPK treatment (except on days 40 and 88), whereas relative abundance of type-II methanotrophs transcripts was high in APK treatment. Note that the different $p m o A$ transcription patterns coincided with $\mathrm{CH}_{4}$ oxidation rates and in vitro $\mathrm{CH}_{4}$ oxidation potentials being much lower in APK than UPK or PK.

\section{Statistical analysis of T-RFLP profiles}

NMDS was used to analyze the effects of nitrogen fertilizer treatment and environmental factors on the community structure of methanotrophs. The results are summarized for roots and rhizospheric soil samples in one ordination diagram (Figure 7a). Soil samples formed a tight cluster characterized by a T-RF indicative for type-II methanotrophs (green triangle), whereas root samples occupied a much larger ordination space together with the T-RFs 

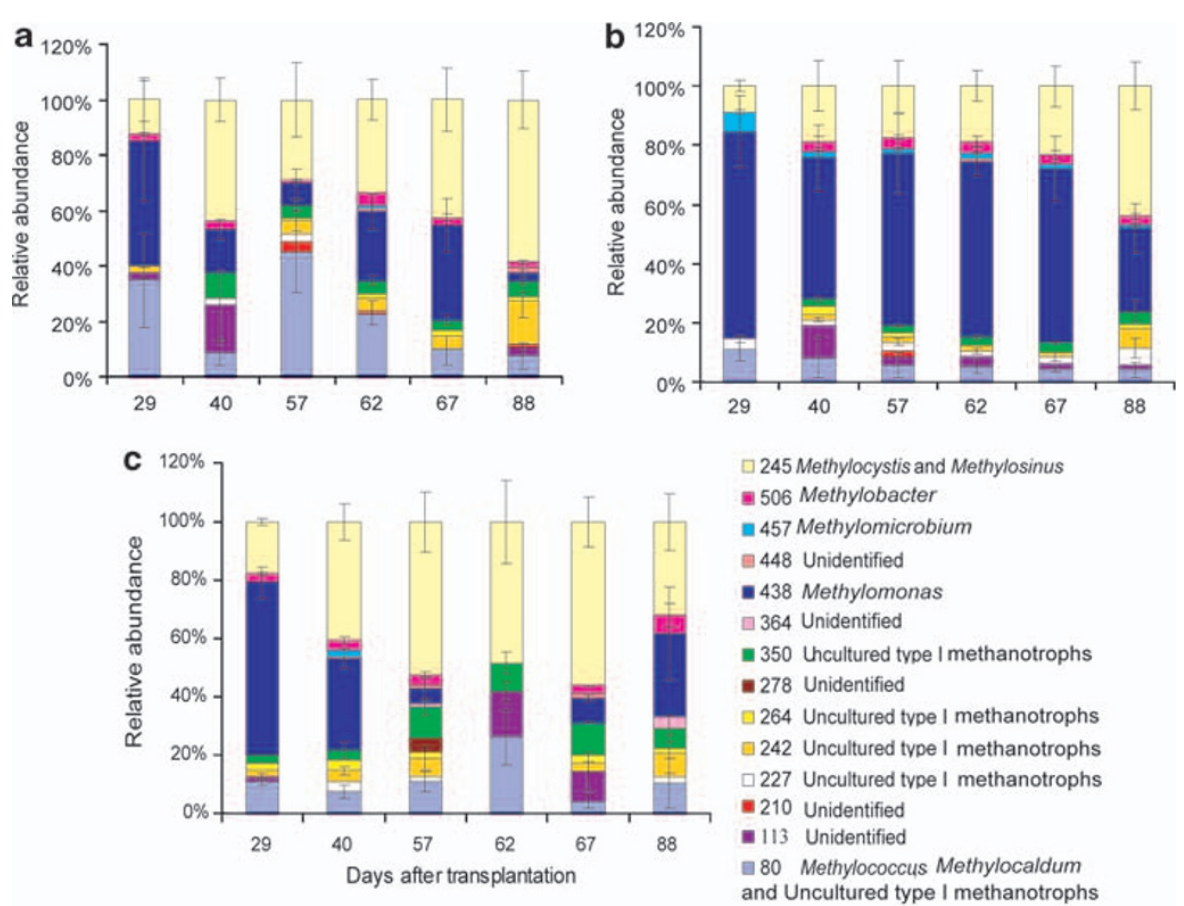

Figure 4 pmoA gene-based T-RFLP profiles from root samples from (a) PK treatment, (b) UPK treatment, and (c) APK treatment from different sampling points. Values are mean \pm s.d. $(n=5-9)$. MspI was used as restriction enzyme. A 244-bp T-RF is representative of typeII methanotrophs; 80, 227, 242, 264, 350, 374, 438, 457, and 506 bp are representative of type-I methanotrophs, whereas 113, 210, 278, 364 , and $448 \mathrm{bp}$ could not be affiliated to any clone sequences.
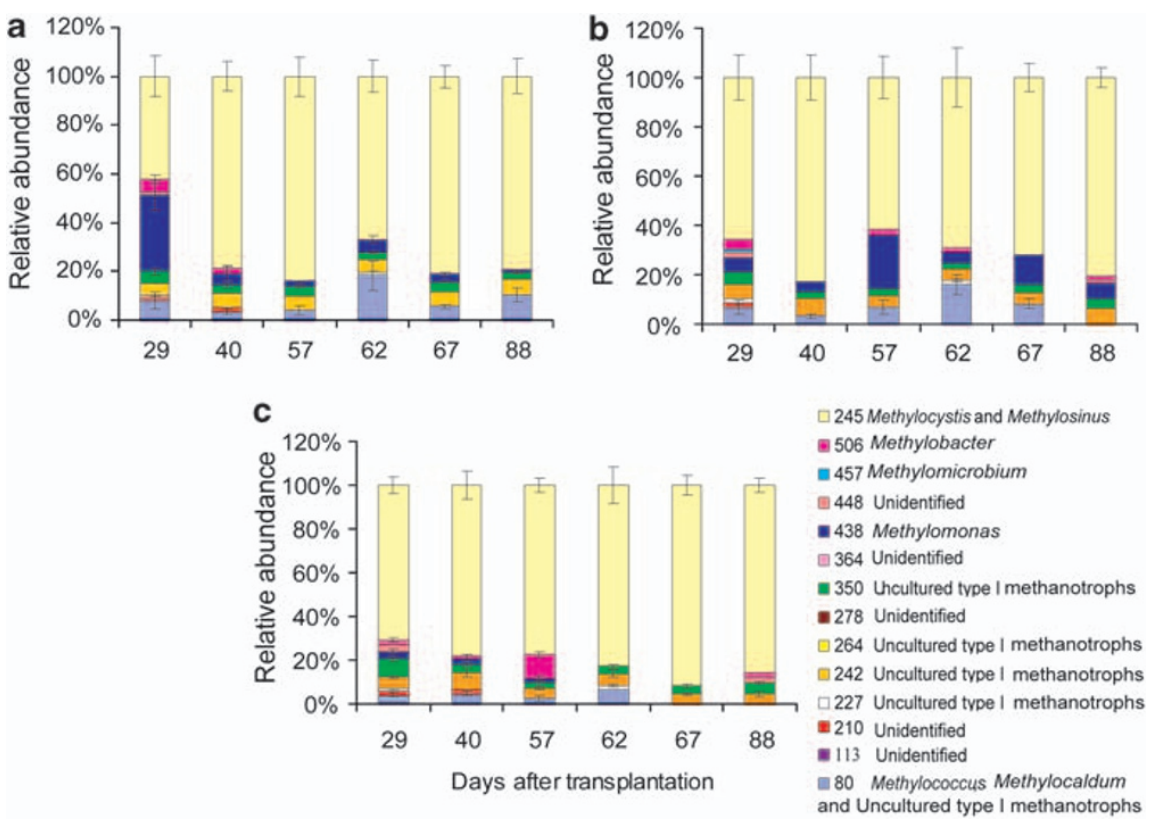

Figure 5 pmoA gene-based T-RFLP profiles from rhizospheric soil samples from (a) PK treatment, (b) UPK treatment, and (c) APK treatment from different sampling points. Values are mean \pm s.d. $(n=5-9)$. For further details, see Figure 4 legend.

characteristic for different type-I methanotrophs (gray and red triangles). Analysis of similarity showed that the total methanotrophic community on roots was significantly affected by the different fertilizer treatments $\left(R^{2}=0.37 ; P<0.001\right)$, whereas that in rhizospheric soil was barely affected $\left(R^{2}=0.06\right)$.

When only the root samples were analyzed by NMDS (Figure 7b), the methanotrophic community of UPK treatment clustered around the T-RF 

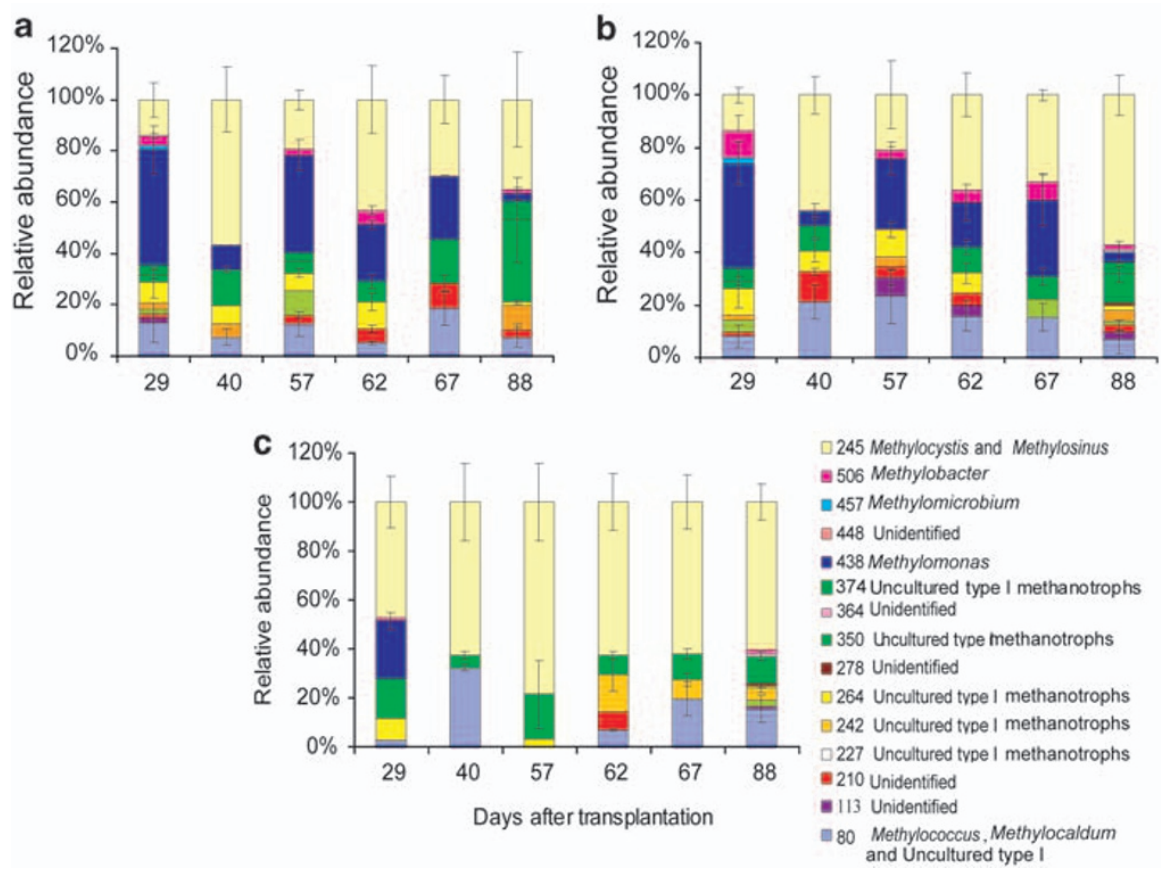

Figure 6 Relative abundance calculated for $p m o A$ transcripts from rhizospheric soil samples from (a) control; PK treatment, (b) UPK treatment, and (c) APK treatment from different sampling points. Values are mean \pm s.d. $(n=5-9)$. For further details, see Figure 4 legend.
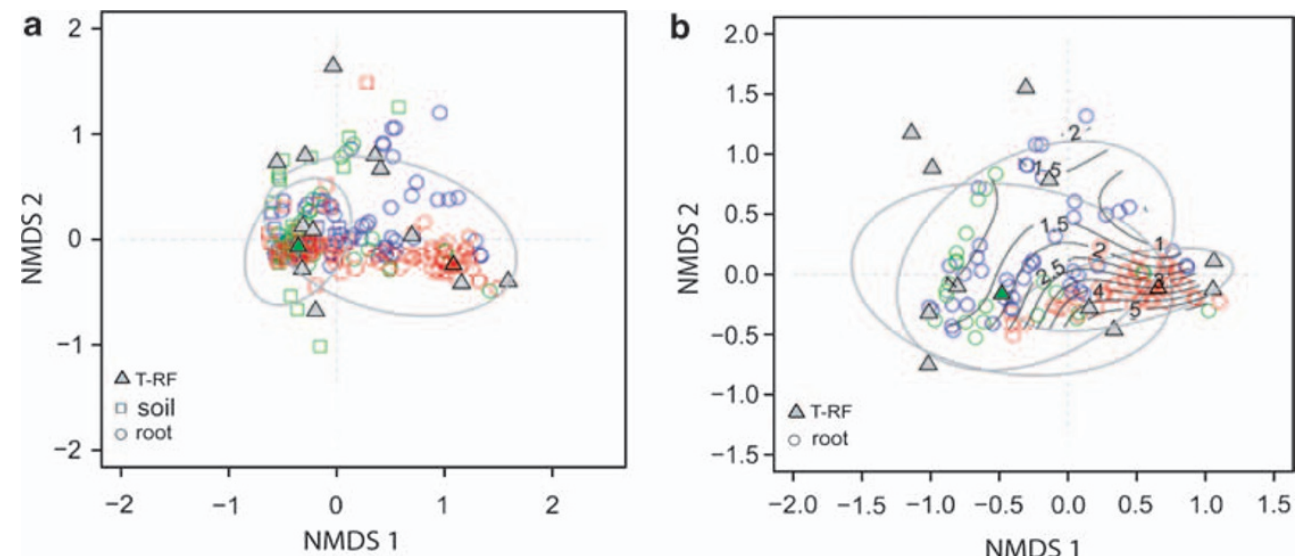

Figure 7 NMDS of pmoA gene (DNA)-based T-RFLP profiles (a) from samples of both rhizospheric soil and roots (non-metric fit, $R^{2}=0.99$; linear fit, $R^{2}=0.97$ ) and (b) from root samples (non-metric fit, $R^{2}=0.99$; linear fit, $R^{2}=0.98$ ). In (a), the $90 \%$ confidence ellipses circumscribe the centroids of soil and root samples and in (b), ellipses circumscribe the centroid of the PK, UPK, and APK treatments; the fit of the methane oxidation rates to the ordination is given by gray isolines overlying the ordination. Gray triangles = T-RF indicative for different type-I methanotrophs, green triangle=T-RF indicative for type-II methanotrophs (Methylocystis and Methylosinus), red triangle $=\mathrm{T}-\mathrm{RF}$ indicative for Methylomonas. Soil and root samples are displayed as squares and circles, respectively, whereas the treatments are color coded as blue $=\mathrm{PK}$, red $=\mathrm{UPK}$, and green $=\mathrm{APK}$.

indicative for Methylomonas (red triangle) falling together with increasing $\mathrm{CH}_{4}$ oxidation rates (Figure 7b). The T-RF indicative for type-II methanotrophs (green triangle), on the other hand, seemed to be characteristic for the community receiving the APK treatment (Figure 7b).

Rhizospheric soil samples were analyzed with respect to total and active methanotrophs using the T-RFLP profiles of $p m o A$ genes (DNA) and pmoA transcripts (mRNA; Figure 8a). The DNA-based samples formed a tight cluster around the T-RF indicative for type-II methanotrophs (green triangle). The mRNA-based soil samples occupied a larger ordination space than the DNA-based samples with different patterns for PK and UPK treatments (Figure 8a). Excluding the DNA-based samples and analyzing only the mRNA-based soil samples showed differentiation of $p m o A$ transcripts in the APK from those in the other treatments (Figure 8b). The transcripts in the APK treatment 

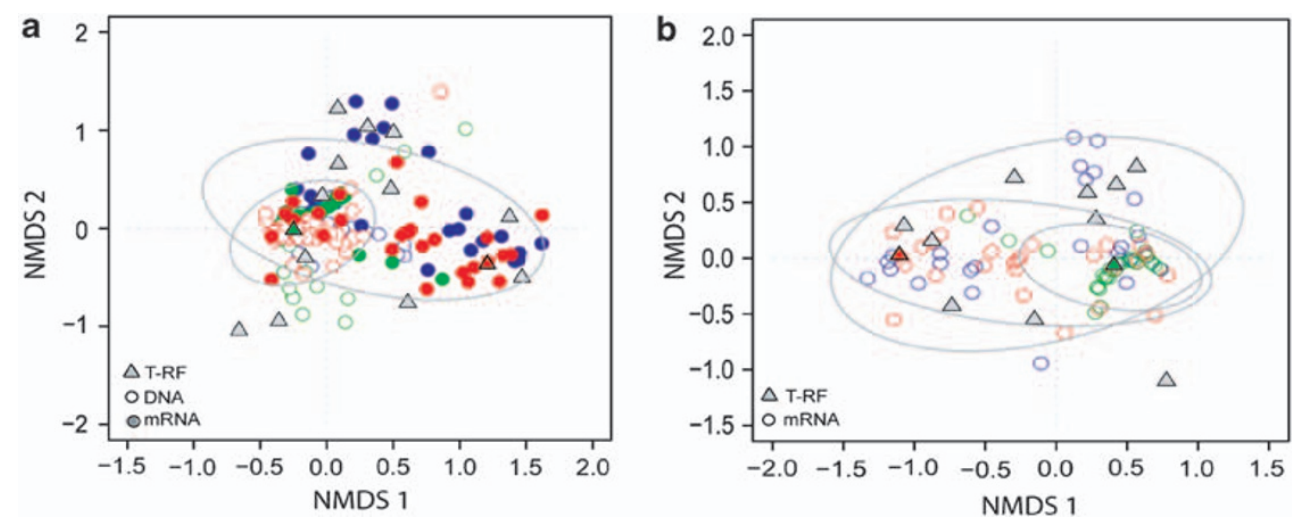

Figure 8 NMDS of T-RFLP profiles from rhizospheric soil using (a) both DNA- and mRNA-based T-RFLP profiles (non-metric fit, $R^{2}=0.99$; linear fit, $R^{2}=0.96$ ) and (b) mRNA-based T-RFLP profiles alone (non-metric fit, $R^{2}=0.99$; linear fit, $R^{2}=0.95$ ). The 90\% confidence ellipses circumscribe in (a) the centroids of DNA-based and mRNA-based samples and in (b) the centroids of mRNA-based samples from PK, UPK, and APK treatments, respectively. Gray triangles = T-RF indicative for different type-I methanotrophs, green triangle $=\mathrm{T}-\mathrm{RF}$ indicative for type-II methanotrophs (Methylocystis and Methylosinus), red triangle = T-RF indicative for Methylomonas. DNA and mRNA samples are displayed as open and closed circles, respectively, whereas the treatments are color coded as blue $=$ PK, red $=\mathrm{UPK}$, and green $=\mathrm{APK}$.

were characterized by type-II methanotrophs (green triangle), whereas the two other treatments contained various type-I methanotrophs (gray and red triangles).

The effect of environmental factors on mRNA patterns was checked with ADONIS. Modeling the mRNA-based dissimilarities in soil as a function of environmental factors and time, the number of tillers and $\mathrm{CH}_{4}$ concentration in bulk soil were highly significant $(P<0.001)$, and both ammonium and $\mathrm{CH}_{4}$ in the rhizospheric soil were significant $(P<0.01)$. The model explained $31.6 \%$ of the total variance.

\section{Discussion}

Three different fertilizer treatments of planted rice microcosms had different effects on $\mathrm{CH}_{4}$ oxidation and populations of methanotrophic bacteria. The composition and differential expression of the methanotrophic community, in particular, were affected by fertilizer treatment, and the effects were different in the rhizospheric soil and on the roots.

Effect of fertilizers on plant growth and $\mathrm{CH}_{4}$ turnover Addition of nitrogen in the form of ammonium (APK) or urea (UPK) resulted in healthier and denser vegetation than addition of only phosphorous and potassium (PK) in the control. Plant development was optimal in APK treatment followed by UPK and PK treatments. These findings corresponded well to the rapid depletion of ammonium in both UPK and APK treatments (Figures 1e and f). However, in APK treatment, low $\mathrm{CH}_{4}$ concentrations (Figures 1c and d) and low $\mathrm{CH}_{4}$ emission rates (Figure 1a) were observed despite well-developed plants. This was probably because of suppression of methanogenesis by high sulfate concentrations in APK treatment (Cai et al., 1997; Minamikawa et al., 2005). Owing to the low $\mathrm{CH}_{4}$ concentrations, rates of $\mathrm{CH}_{4}$ oxidation were also low (Figure 1b).

Rates of emission and oxidation of $\mathrm{CH}_{4}$ were similar in PK and UPK treatments indicating no nitrogen effect on $\mathrm{CH}_{4}$ oxidation activity (Figures 1a and b). Similar observations were made in earlier studies (Dunfield et al., 1995; Delgado and Mosier, 1996; Cai and Yan, 1999; Bykova et al., 2007). However, the potential for $\mathrm{CH}_{4}$ oxidation in the rhizospheric soil was significantly $(P<0.05)$ higher in the nitrogen treatments (APK only in the beginning, UPK throughout) than in the control (PK), thus indicating a stimulating effect of nitrogen fertilization on the methanotrophic community (Figure 2). In fact, a potential for $\mathrm{CH}_{4}$ oxidation was detected at all fertilizer regimes and all growth stages consistent with the detection of $p m o A$ expression (Figure 6). This result is consistent to the findings reported by Bodelier et al. (2000b), who have also found a higher potential activity after nitrogen (urea or $\left.\left(\mathrm{NH}_{4}\right)_{2} \mathrm{HPO}_{4}\right)$ addition to soil slurry as compared with unfertilized soil. However, the pattern of $\mathrm{CH}_{4}$ oxidation potential was not coupled with $\mathrm{CH}_{4}$ emission rates, probably because of opposing effects on $\mathrm{CH}_{4}$ production versus $\mathrm{CH}_{4}$ oxidation. On the one hand, $\mathrm{N}$-fertilization probably stimulated $\mathrm{CH}_{4}$ production by increasing rice plant growth and increasing the carbon supply through the root exudates for methanogens (Bodelier et al., 2000a; Schimel, 2000; Dan et al., 2001). On the other hand, $\mathrm{N}$-fertilization probably also stimulated the growth and activity of methanotrophs, leading to reduced net $\mathrm{CH}_{4}$ efflux because of the increased $\mathrm{CH}_{4}$ oxidation rate (Bodelier et al., 2000b). As a consequence, no differential effect was observed in either $\mathrm{CH}_{4}$ emission or $\mathrm{CH}_{4}$ oxidation between PK and UPK treatment. However, a transient stimulation of $\mathrm{CH}_{4}$ 
oxidation was observed in UPK treatment after the fertilizer addition on day 57 (Figure 1b). A similar result was reported by Kruger and Frenzel (2003).

\section{Effect of fertilizers on the root methanotrophic community}

The root methanotrophic community was dominated by type-I methanotrophs, but the relative abundance changed over the rice-growing season and was affected by the type of fertilizer (Figure 4) used. The relative abundance of both type-I and type-II methanotrophs exhibited stronger seasonal dynamics in PK and APK treatments, which suggested plant growth-related variations upon release of $\mathrm{O}_{2}$ and organic substances as controls of microbial dynamic on rice roots (Ikenaga et al., 2003). In UPK treatment, however, temporal changes were relatively minor. We speculate that in UPK treatment, $\mathrm{CH}_{4}, \mathrm{O}_{2}$, and $\mathrm{NH}_{4}^{+}$concentrations were probably sufficient allowing a relatively consistent and stable methanotrophic community with dominant type-I methanotrophs throughout the rice-growing season (except on day 88). NMDS ordination of community patterns showed that the root methanotrophic community of UPK treatment was different from those of the other treatments. It furthermore indicated a coincidence between elevated $\mathrm{CH}_{4}$ oxidation activity and the methanotrophic community structure with Methylomonas spp., in particular, as indicator species (Figure 7b). In contrast, Methylocystis and Methylosinus were indicative for the active population in rhizospheric soil in APK treatment (Figure 8b). These differences in indicator species are relevant as (i) Methylomonas species can assimilate urea as N-source (Bowman, 2006) and (ii) type-II methanotrophs (Methylocystis spp. and Methylosinus spp.) are known to survive under adverse conditions (Hanson and Hanson, 1996) such as low $\mathrm{CH}_{4}$ concentrations in the APK treatment.

\section{Effect of fertilizers on the soil methanotrophic community}

The soil methanotrophic community was different from the root community and was generally dominated by type-II methanotrophs (Figure 5). The community was quite uniform across different fertilizer treatments and growth stages as shown by NMDS statistical analysis (Figures 7a and 8a). It has repeatedly been reported that rhizospheric soil samples are predominantly populated by type-II methanotrophs (Gilbert and Frenzel, 1995; Henckel et al., 2000; Eller and Frenzel, 2001; Shrestha et al., 2008). The high relative abundance of type-II methanotrophs in soil might be due to their ability of forming cysts or spores.

However, a more dynamic pattern was revealed from the analysis of $p m o A$ transcripts, which showed a more diverse and changeable pattern of
T-RFs than those of $p m o A$ genes (Figures 6 and $8 \mathrm{~b}$ ). Interestingly, the pmo $A$ transcript patterns were only dominated by type-II methanotrophs in APK treatment, whereas type-I methanotrophs dominated in the other treatments (Figure 6). The relatively large activity of type-II methanotrophs in APK treatment may be due to the low $\mathrm{CH}_{4}$ concentrations, as discussed above. However, the relatively large activity of type-I methanotrophs in PK and UPK treatments is intriguing, as type-I populations were only relatively small in $p m o A$ gene-based study.

Earlier studies that were restricted to either soil slurries (Bodelier et al., 2000b; Noll et al., 2008) or single-time point sampling (Qiu et al., 2008) showed that the type-I methanotrophs were active after addition of nitrogen fertilizer. Here, we have shown in a comprehensive study that type-I methanotrophs transcribe $p m o A$ throughout the rice-growing season irrespective of nitrogen fertilizer treatment. Thus, type-I methanotrophs probably were responsible for in situ $\mathrm{CH}_{4}$ oxidation, although they constituted only the minor part of the total methanotrophic community. Hence, it seems that activity of type I generally was higher than that of type-II methanotrophs when $\mathrm{CH}_{4}$ concentrations were sufficiently high. ADONIS statistics confirmed that $\mathrm{CH}_{4}$ concentration together with ammonium concentration were significant environmental variables in rhizospheric soil affecting $p m o A$ transcript patterns of type-I methanotrophs. Methylomonas was the most important indicator species for UPK treatment and uncultured type-I methanotrophs (T-RFs 80, 374, and 350) were indicator species for PK treatment (Figure 8b).

\section{Conclusions}

The determination of $p m o A$ gene-based T-RFLP profiles and subsequent affiliation to clone sequences and NMDS ordination showed that different fertilizers significantly affected the methanotrophic community structure; however, the effect was stronger on the roots and weaker in the rhizospheric soil. Furthermore, populations of type-I methanotrophs were dominant on root, whereas type-II methanotrophs were dominant in rhizospheric soil indicating niche differentiation within rice rhizosphere region. In contrast, $p m o A$ transcript-based T-RFLP analysis of rhizospheric soil showed type I as the predominantly active methanotrophs both in PK and UPK treatments albeit their populations were relatively smaller than those of type-II methanotrophs. These observations indicate that type I are the more dynamic methanotrophs that rapidly become active and grow when conditions are favorable, such as in the rhizosphere and even more on the roots. Type-II methanotrophs, in contrast, seem to be better adapted to less favorable conditions, as found in the soil rather than on the roots, and under conditions in which $\mathrm{CH}_{4}$ production was suppressed (APK treatment) resulting in low $\mathrm{CH}_{4}$ concentrations. 


\section{Acknowledgements}

We thank Elisabetta Lupotto and the C.R.A. Unità di Ricerca per la Risicoltura for support at the rice fields in Vercelli, Italy. This study was financially supported by grants from the Fonds der Chemischen Industrie to RC and by the Deutsche Forschungsgemeinschaft (ESF and EuroDIVERSITY-METHECO) to PF.

\section{References}

Altschul SF, Gish W, Miller W, Myers EW, Lipman DJ. (1990). Basic local alignment search tool. J Mol Biol 215: 403-410.

Bodelier PLE, Hahn AP, Arth IR, Frenzel P. (2000a). Effects of ammonium-based fertilisation on microbial processes involved in methane emission from soils planted with rice. Biogeochemistry 51: 225-257.

Bodelier PLE, Roslev P, Henckel T, Frenzel P. (2000b). Stimulation by ammonium-based fertilizers of methane oxidation in soil around rice roots. Nature 403: 421-424.

Bosse U, Frenzel P, Conrad R. (1993). Inhibition of methane oxidation by ammonium in the surface-layer of a littoral sediment. FEMS Microbiol Ecol 13: 123-134.

Bourne DG, McDonald IR, Murrell JC. (2001). Comparison of pmoA PCR primer sets as tools for investigating methanotroph diversity in three Danish soils. Appl Environ Microbiol 67: 3802-3809.

Bowman J. (2006). The methanotrophs. The families Methylococcaceae and Methylocystaceae. In Dworkin M (ed). The Prokaryotes. Springer: New York, USA, 5: 266-289.

Bykova S, Boeckx P, Kravchenko I, Galchenko V, Van Cleemput O. (2007). Response of $\mathrm{CH} 4$ oxidation and methanotrophic diversity to $\mathrm{NH} 4+$ and $\mathrm{CH} 4$ mixing ratios. Biol Fertil Soils 43: 341-348.

Cai ZC, Xing GX, Yan XY, Xu H, Tsuruta H, Yagi K et al. (1997). Methane and nitrous oxide emissions from rice paddy fields as affected by nitrogen fertilisers and water management. Plant Soil 196: $7-14$.

Cai ZC, Yan XY. (1999). Kinetic model for methane oxidation by paddy soil as affected by temperature, moisture and $\mathrm{N}$ addition. Soil Biol Biochem 31: 715-725.

Dan JG, Kruger M, Frenzel P, Conrad R. (2001). Effect of a late season urea fertilization on methane emission from a rice field in Italy. Agric Ecosyst Environ 83: 191-199.

Delgado JA, Mosier AR. (1996). Mitigation alternatives to decrease nitrous oxides emissions and urea-nitrogen loss and their effect on methane flux. J Environ Qual 25: 1105-1111.

Dunbar J, Ticknor LO, Kuske CR. (2001). Phylogenetic specificity and reproducibility and new method for analysis of terminal restriction fragment profiles of 16S rRNA genes from bacterial communities. Appl Environ Microbiol 67: 190-197.

Dunfield PF, Topp E, Archambault C, Knowles R. (1995). Effect of nitrogen fertilizers and moisture-content on Ch4 and N2o fluxes in a humisol-measurements in the field and intact soil cores. Biogeochemistry 29: 199-222.

Eller G, Frenzel P. (2001). Changes in activity and community structure of methane-oxidizing bacteria over the growth period of rice. Appl Environ Microbiol 67: 2395-2403.

Gilbert B, Frenzel P. (1995). Methanotrophic bacteria in the rhizosphere of rice microcosms and their effect on porewater methane concentration and methane emission. Biol Fertil Soils 20: 93-100.

Hanson RS, Hanson TE. (1996). Methanotrophic bacteria. Microbiol Rev 60: 439-471.

Henckel T, Roslev P, Conrad R. (2000). Effects of O-2 and $\mathrm{CH} 4$ on presence and activity of the indigenous methanotrophic community in rice field soil. Environ Microbiol 2: 666-679.

Hutsch BW, Webster CP, Powlson DS. (1994). Methane oxidation in soil as affected by land-use, soil-Ph and N-fertilization. Soil Biol Biochem 26: 1613-1622.

Ikenaga M, Asakawa S, Muraoka Y, Kimura M. (2003). Bacterial communities associated with nodal roots of rice plants along with the growth stages: estimation by PCR-DGGE and sequence analyses. Soil Sci Plant Nutr 49: 591-602.

Kolb S, Knief C, Stubner S, Conrad R. (2003). Quantitative detection of methanotrophs in soil by novel pmoAtargeted real-time PCR assays. Appl Environ Microbiol 69: $2423-2429$.

Kruger M, Eller G, Conrad R, Frenzel P. (2002). Seasonal variation in pathways of $\mathrm{CH} 4$ production and in $\mathrm{CH} 4$ oxidation in rice fields determined by stable carbon isotopes and specific inhibitors. Glob Change Biol 8: 265-280.

Kruger M, Frenzel P. (2003). Effects of N-fertilisation on CH4 oxidation and production, and consequences for $\mathrm{CH} 4$ emissions from microcosms and rice fields. Glob Change Biol 9: 773-784.

Kruger M, Frenzel P, Conrad R. (2001). Microbial processes influencing methane emission from rice fields. Glob Change Biol 7: 49-63.

Ludwig W, Strunk O, Westram R, Richter L, Meier H, Yadhukumar et al. (2004). ARB: a software environment for sequence data. Nucleic Acids Res 32: 1363-1371.

Minamikawa K, Sakai N, Hayashi H. (2005). The effects of ammonium sulfate application on methane emission and soil carbon content of a paddy field in Japan. Agric Ecosyst Environ 107: 371-379.

Neue HU, Wassmann R, Kludze HK, Bujun W, Lantin RS. (1997). Factors and processes controlling methane emissions from rice fields. Nutrient Cycling Agroecosyst 49: 111-117.

Noll M, Frenzel P, Conrad R. (2008). Selective stimulation of type I methanotrophs in a rice paddy soil by urea fertilization revealed by RNA-based stable isotope probing. FEMS Microbiol Ecol 65: 125-132.

Oksanen J. (2008). Multivariate analysis of ecological communities in R: vegan tutorial. [WWW document]. URL http://cc.oulu.fi/ jarioksa/opetus/metodi/vegantutor.pdf. 2-13-2008. Ref Type: Internet Communication.

Qiu QF, Noll M, Abraham WR, Lu YH, Conrad R. (2008). Applying stable isotope probing of phospholipid fatty acids and rRNA in a Chinese rice field to study activity and composition of the methanotrophic bacterial communities in situ. ISME J 2: 602-614.

Schimel J. (2000). Global change-rice, microbes and methane. Nature 403: 375-377.

Shrestha M, Abraham WR, Shrestha PM, Noll M, Conrad R. (2008). Activity and composition of methanotrophic bacterial communities in planted rice soil studied by flux measurements, analyses of pmoA gene and stable 
isotope probing of phospholipid fatty acids. Environ Microbiol 10: 400-412.

Shrestha PM, Kube M, Reinhardt R, Liesack W. (2009). Transcriptional activity of paddy soil bacterial communities. Environ Microbiol 11: 960-970.
Steudler PA, Bowden RD, Melillo JM, Aber JD. (1989). Influence of nitrogen-fertilization on methane uptake in temperate forest soils. Nature 341: 314-316.

Wickham H. (2007). Reshaping data with the reshape package. J Stat Softw 21: 1-20.

Supplementary Information accompanies the paper on The ISME Journal website (http://www.nature.com/ismej) 